tum, tilting up the calculus, it was remored without any emplorment of the forceps. The stone was round, and of about the size of a small horse-bean. The amount of blood lost during the operation was trifling. No other stone could be detected. A sponge was now applied to the wound, and retained in position by a bandage.

To detail the daily progress of the case would be tedious, and without any practical importance. When the patient first passed urine after the operation, a few drops escaped by the urethra; but in less than forty-eight hours this was reversed, and he retained the urine for four or five hourslonger, in fact, than he had done for months. On the third day, I allowed him to get up and have his clothes on. The wound appeared almost healed; in fact, he considered himself well. On the subsequent day to the operation he appeared slightly feverish, but this passed off almost immediately. In a few days, he brought over to my surgery the bandages; and he appeared perfectly well.

RexskKs. Had I been in the position of meeting with frequent examples of this disease, I should have hesitated before laying an isolated case before the members of this Branch; but when I reflected that years might pass, and no cases present themselres, I considered it the wiser plan to add my mite of experience at once.

I must confess that my own feelings were not at first so farourable to the operation. I attribute this not to the operation itself, but to my own preconceived notions. I expected to find a larger, though not a large stone; and hence I continued efforts at dilatation, which were unnecessary, and which rendered the operation much longer. These feelings were very speedily dissipated by finding the recovery so rapid. Instend of the usual anxieties attendant on the lateral operation, I was able at once to set my mind at rest; and, even if the rapid recovery were the only advantage attending this modification, it is a point of the utmost importance, where a family is dependent on the exertions of the sufferer.

When I reflect on the dangers of the lateral operation, éren when skilfully performed by the experienced handdangers many of which, though within the ken, are beyond the control of the operator-I cannot but think that this simple modification of the Marian operation, as recommended by Mr. Allarton, is a boon to the profession, and one that will increase in favour in proportion to the extent of its trials.

Blaina Iron Works, Mrarch 1835.

\section{PREVENTION OF ENTRANCE OF AIR IN PARACENTESIS THORACIS.}

\section{BY T. WALKER, M.D.}

DR. WAtsor states, as one of the most important objections to the operation of paracentesis thoracis, the probable entrance of air into the pleural sac; and, as I regard this operation as one by which great and immediate relief may be afforded, under circumstances of extreme distress, and when death from suffocation is imminently impending, I consider it important to shew that the admission of air is perfectly and easily aroidable hy a very simple arrangement.

Ihet a piece of quill, fitted to the tube of the canula, be prepared by wrapping round it, and securing with a bit of thread, a small piece of thin wash leather or sheepskin, rendered limp by wetting it. Immediately on withdrawing the trocar, this quill is introduced into the canula: the wet leather forms a pendulous prolongation of the tube, an inch and a half long, or a little more, through which the fluid will flow freely; but the moment that the slightest act of suction takes place, which, as the chest gets empty, invariably happens, it will act as a valve, and prerent the possibility of any air entering by the tube of the canula.

I need not here state the precautions necessary in order to prevent, whether during the operation or after it, the entrance of air by the opening made by the trocar, as they are generally known, and would, as a matter of course, be adopted.

I have never performed the operation of paracentesis thoracis, unless when it was evidently and urgently required. I have nerer seen it fail to gire great and immediate relief. In all cases of mere serous effusion, the patient has recovered; and in the only case in which the patient died-one of empyema with tubercular phthisis-although ho ultimately sank from the pulmonary disease, the urgent distress from dyspnoa, threatening immediate dissolution, was entirely relieved, and his life was prolonged for several months after the operation.

I saw to-day a young man, now in good bealth, from whose left pleural cavity I drew off, on the 28th of January, ten pints of serum, the effusion consequent to an attack of subacute pleuritis, of at least four months' standing. I only refer to this case, however, in order to say that using the simple apparatus which $I$ have described, not a particle of air entered the pleural sac; nor has this disagreeable incident ever occurred, either in ny own hands, when I have used this plan, or in those of any of my friends, who have at my suggestion adopted the same modification of means as simple as they are effectual.

Peterborough, Brarch 2C, 18:55.

\section{REPORTS OF SOCIFTIES.}

\section{ROYAL MEDICAL AND CHIRURGICAL SOCIETY. \\ TUESDAY, Marci 13TH, 1855 . \\ Cesar Hawkins, Esq., l'resident, in the Chair.}

On taking the chuir, Mr. Hawkiss thanked the Fellows for the bonour they had done him in electing him their President. Alluding to the disagreements which had taken place during the past year, he trusted that they would not be renewed, and that the acute disease under which the Society had laboured would not become a chronic one.

NOTES ON IITHOTRITY, WITI AN ACCOCNT OF THE RESLLTS OF the OPERATION IY THE AUTHOR'S PRACTICE. BY SIR B. C. BRODIE, B.IRT.

The anthor announced that his chief objects were-to communicate, in a series of notes, some observations as to those circumstances which are especially deserving of attention, with a view to the success of the operation; to give a brief but accurate account of the actual results of his own practice; and to add some observations as to the amount of danger involved in the operation by crushing, compared with that which belongs to lithotomy. He adduced reasons why this operation was not applicable to the period of youth, nor generally common or necessary in females. He preferred the forceps worked by a screw to that in which the force is applied by means of a rack, since the latter, though affording sorne advantages in the way of greater expedition, must be manifestly deficient in power as compared with the screw. The nuthor remarked that no prudent surgeon would willingly undertake this operation unless the bladder admitted of the injection and retention of from four to six ounces of tepid water; and that where this power had been lost, it had in all his cases but one been restored by keeping the patient in the recumbent position for seven or fourteen days, and injecting the bladder daily. He then described the steps of the operation, urging the great necessity for the gentlest possible manipulation of the forceps, that injury may be aroided, pain diminished, and, by consequence, the bladder rendered less prone to contract upon its contents; that, with these points in view, the forceps should never be used as a sound for the purpose of exploring the bladder or ascertaining the position of the calculus, but that the convex part of its curved extremity should be brought into contact rith, and gently pressed against, the posterior and lower surface of the bladuer by the elevation of its handle; that if, when in this position, on the blades being separated, the stone does not fall into it ly its own weight, the instrument may be slightly struck on one of its sides, which slight concussion will probably dislodge the calculus from its fixed position and cause it to fall; if unsuccessful in this, the forceps may be very cantiously turned to one side or the other, and the same rules followed in that position as before; but a freer use of the instrument should never be made, not eren in 